\title{
AN APPARATUS FOR THE COLLECTION OF PLANKTON IN THE IMMEDIATE VICINITY OF THE SEA-BOTTOM
}

\author{
By J. Bossanyi \\ Dove Marine Laboratory, Cullercoats
}

(Text-figs. I-3)

In connexion with a study of plankton-benthos interrelationships off the coast of Northumberland, an apparatus was designed for the collection of plankton in the immediate vicinity of the sea-bottom, a layer usually missed by ordinary plankton sampling gear. The present account is a brief description of this apparatus, together with some notes on its handling at sea and the work carried out with it on board the Dove Marine Laboratory's boat, the Pandalus II.

I was fortunate in having the willing co-operation of numerous people who helped in various ways, and to whom I am very greatly indebted. These included my father, Mr E. Bossanyi; Mr T. E. F. Sanderson of Eastcote, Middlesex; Prof. A. C. Hardy, Oxford University; Dr C. E. Lucas, Fishery Laboratory, Aberdeen; Prof. A. D. Hobson, Director of the Dove Marine Laboratory; Dr H. O. Bull, Assistant Director; Messrs Ellis and Co., Engineering Works, Swalwell, County Durham; the Department of Mechanical Engineering of King's College, Newcastle upon Tyne; and the entire scientific, boat and technical staff as well as research students at the Dove Marine Laboratory. Without them, the design, construction and employment of the apparatus would not have been possible.

\section{DESCRIPTION OF THE APPARATUS}

The present apparatus differs from previous designs of bottom-plankton nets (e.g. Russell, I928; Hardy \& Lucas, personal communication), chiefly in being provided with a closing device which operates only by contact with the sea-bottom. It thus eliminates the disadvantage of the earlier designs which necessarily fished both on the way down to and up from the bottom. At the same time, the nature of the closing mechanism avoids the necessity of any extra ropes or cables for messengers etc., and allows the apparatus to be shot rather like a beam trawl from a boat that is slowly moving as well as from a stationary one.

The apparatus is essentially a sledge constructed of tubular steel ( $\mathrm{I} \frac{1}{4}$ in. diameter) on runners, on which a removable plankton net with bucket is mounted, and bearing in addition two closing doors which fit over the mouth of the net (Figs. I-3). 
The frame consists of two parts, each made in one piece with all joints firmly welded so as to be both strong and waterproof. These are the sledge frame (Fig. 3A), which bears the runners $(u)$ and to which the ropes are shackled by means of eyes, and the net frame (Fig. 3B), which is mounted on its vertical bars. This frame can thus move vertically on the sledge frame with a total range of about a foot and can be clamped at any level within this range by wing nuts at $(v)$. The actual net with its bucket fits into the net frame, and is fastened at the front end by hooks fitting into perforated steel laths $(w)$ on the net frame, whilst at the rear end the bottom of the bucket is fixed to a steel plate (shown in black) by a wing nut. The net frame bears a coarse steel gauze on its lower aspect to protect the net from below, and also the doors, each of which is welded to it by two strong hinges at $\left(x, x^{\prime} ; y, y^{\prime}\right)$. All cross-bars of both frames are above the level of the runners.

The net (Fig. I) is a cone of four sections sewn together, and is constrained into a rectangular shape at its mouth. As in ordinary plankton nets, it has a canvas rim at each end for attachment, achieved, in this net, by means of the hooks already mentioned at the front, and the bucket at the rear.

The bucket (Fig. I) is constructed on the lines of Hensen's quantitative bucket (Hensen, I895, pp. 69-7I), with a non-filtering lower portion from which there is an outflow (corked during a tow), and a filtering upper portion consisting of the finest bolting silk (200 meshes/in.) which enables the bucket to be used with nets of that or coarser mesh. It is fastened to the net by a threaded rim which screws with a few turns into a ring clamped to the rear canvas of the net. When several nets of different mesh but of the same size and shape are in use therefore, one and the same bucket can easily be fixed to any one net, provided each of these has its own threaded ring clamped to it.

The doors (Fig. 3C) each consist of two steel plates movably bolted to one another. The door proper is permanently welded to the net frame by the hinges already referred to, and closes half of the net mouth-opening. The arm projects out at right angles to the whole apparatus when the door is shut, and its lower end projects 2-3 in. or more below the level of the runners. Because the arm is adjustable relative to the door proper, it can always be kept at this level whatever the vertical position of the net frame in the sledge frame may be. When the apparatus is lowered to the sea-bed and dragged forwards, the lower end of each arm thus digs into the ground and is swept back so as to lie parallel with the frame, thereby opening the doors forwards. The adjustable springs which are attached to the upper margin of the door proper and the upper net frame bar on each side $\left(z, z^{\prime}\right)$ are extended and put under tension by this action, so that when the apparatus and hence the arms are lifted clear of the bottom, they pull the doors shut. Care was taken in the design to ensure that the areas of door and arm on each side of the points of attachment to the hinges are equal, thus cancelling out to all intents and purposes the effect of water resistance. The only effective forces on the 'open- 
shut' mechanism therefore are the resistance of the sea-bottom to the arms and the pull of the springs.

The dimensions of the whole apparatus (maximum length 7 , maximum width 3 , and maximum height $2 \mathrm{ft}$. approximately), are determined by those of the net it contains. These in turn are determined by two factors: the net must be large enough to obtain a reasonable catch in a short time, and its filtering area must be large enough relative to its mouth area to allow efficient filtering to take place at ordinary plankton net towing speeds (about I knot). A consideration of the dimensions of various commonly used nets such as described by Ostenfeld \& Jespersen (I924) and Künne (I929, I933) led to the conclusion that a ratio of 6 : I would in practice meet this requirement, and the present net was made accordingly.

\section{Handling the Apparatus at Sea}

Owing to its considerable weight (about $I_{2} \frac{1}{2}$ cwt.) the apparatus cannot be handled without either a derrick or a davit with a winch. Given these requirements, together with a minimum of three people who have learnt the necessary drill for shooting and hauling, the apparatus can be quite comfortably used even in a moderately choppy sea, though in the latter case the steersman must take care to keep the vessel stern into the waves to reduce swaying to a minimum. Two fairly heavy ropes are necessary ( $2 \frac{1}{4} \mathrm{in}$. circumference), one of which, the lifting rope, is used solely for lowering the apparatus to the bottom and later raising it from just beneath the surface on to the deck, whilst the other, the tow rope, is employed for towing the apparatus along the bottom and hauling in to just below the surface afterwards. With a davit of sufficient height, the apparatus could be hauled in completely by the tow rope and swung in over the deck, hanging in a vertical position. The disposition of the ropes is shown in Fig. 2.

A good deal of information as regards the working of the apparatus when being towed along the bottom could be gleaned from the presence and position of scratch marks on the runners and lower ends of the arms. These parts were therefore often coated with paint sometime before a haul, and scratch marks observed afterwards (see Fig. 2).

\section{WORK DONE WITH THE APparatus, I949-50}

The apparatus described here is of course not suitable for use on rocky bottoms. It is doubtful whether any type of sledge arrangement can be used effectively on such grounds. The work carried out with it has been confined to sandy and hard muddy bottoms of which there are great stretches in shallow and deep water off the coast of Northumberland. On these bottoms the apparatus has been found to work very well and a considerable amount of material has been collected with it. It is also planned to use the apparatus on softer muddy 


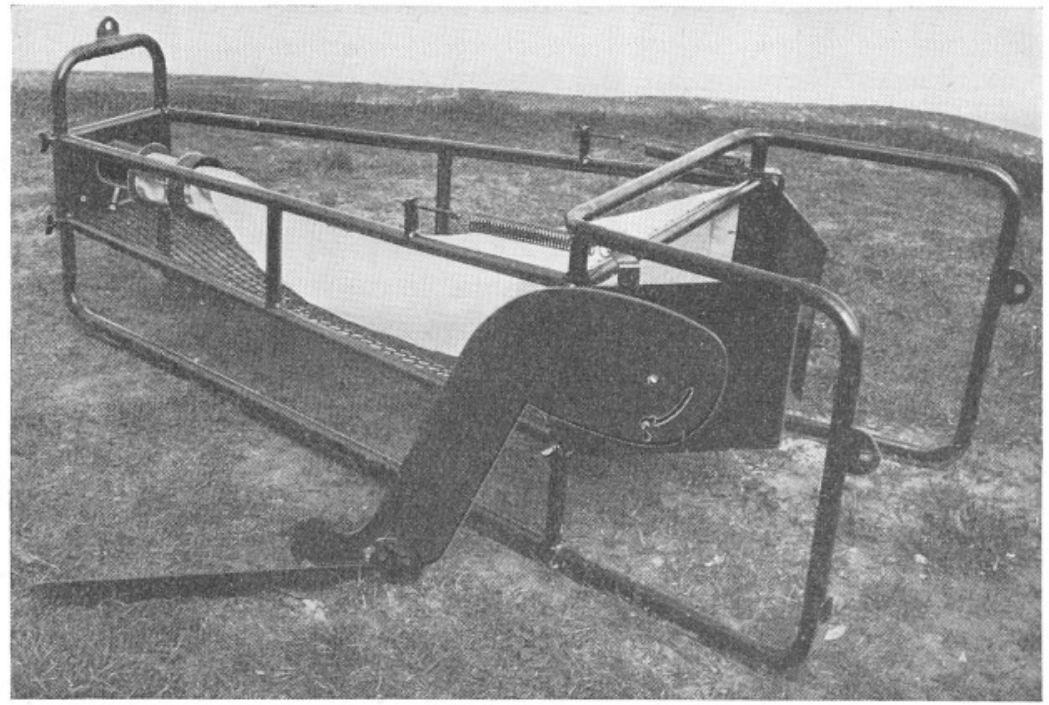

Fig. I. The whole apparatus assembled with the doors partially opened. The extension on the arm of the door was an experimental addition which proved to be unnecessary.

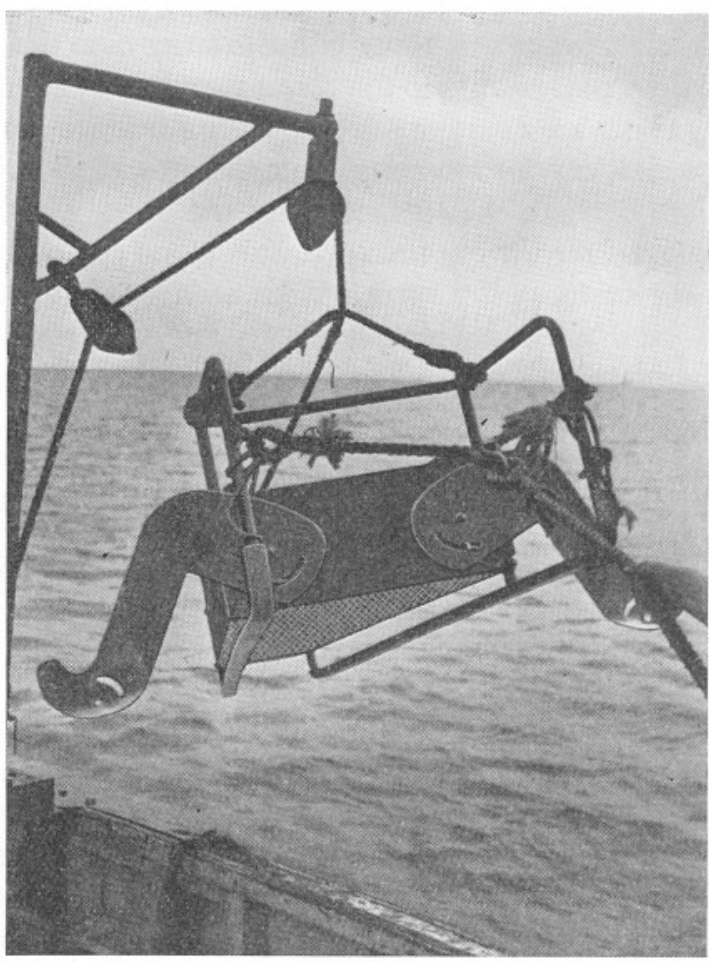

Fig. 2. The apparatus hanging on the davit and about to descend into the sea, showing the davit swung out overboard, and the lifting and tow ropes. Note also the areas scratched clean on the lower ends of the arms during a previous tow. 
bottoms, which may present some difficulties owing to its considerable weight, and on shingle and gravelly areas. Collections of plankton above rocky bottoms will have to be tackled by different means, e.g. using a pump and hose, for the smaller species especially. Apart from various trial runs at different places in the initial stages of the work, the apparatus was used fairly regularly with a net

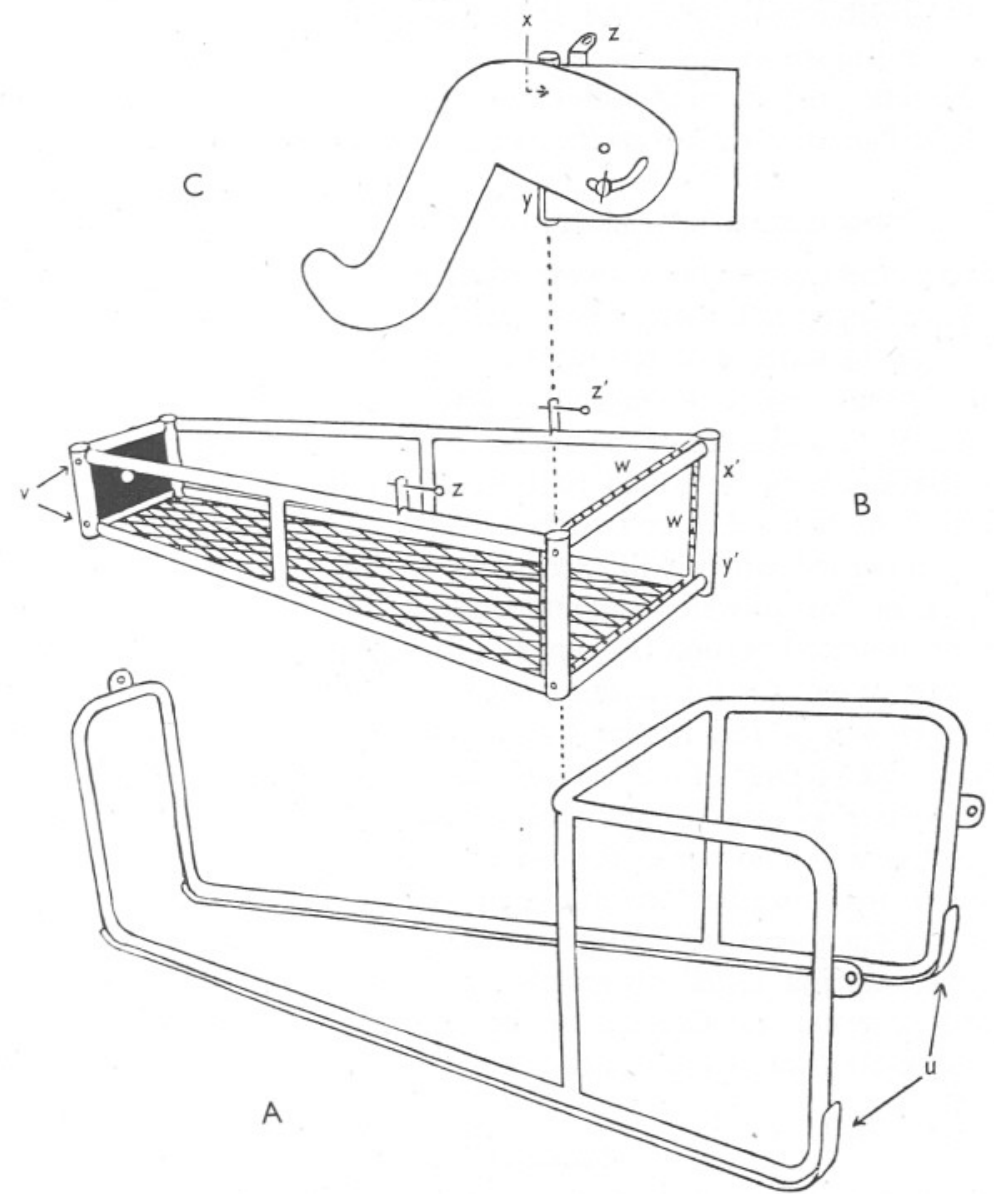

Fig. 3. Portions of the apparatus: A, the sledge frame; B, the net frame; c, one of the doors complete with arm. $u$, the runners; $v$, threaded holes for wing nuts for clamping net frame on sledge frame, also present at the front end; w, steel laths with holes 3 in. apart for hooks of net; $x, x^{\prime}, y, y^{\prime}$, position of hinges on door and net frame; $z, z^{\prime}$, points of attachment of springs on door and net frame.

of 40 meshes/in. at two stations in the vicinity of Blyth harbour, Northumberland. One of these was in Blyth Bay a few hundred yards offshore in 5-6 fathoms on a sandy bottom; the other in Cambois Bay (north-east of Blyth) in I3-I5 fathoms on a bottom of sandy mud. Collections were made at different states of the tide, at different times of the day, and also at night. The 
duration of tow varied somewhat according to circumstances, but was usually $20 \mathrm{~min}$. to ensure an adequate catch, though this was often much more than sufficient.

The catches obtained were not appreciably contaminated with sand or mud if the apparatus had been working properly, even with the net frame fixed at its lowest possible position on the sledge frame. Small coal particles, extremely abundant in the sea in this area, however, often contaminated the catches and had to be separated off in the laboratory later.

A detailed analysis of the catches will be discussed in a subsequent paper.

\section{Possible Improvements In Design of the Apparatus}

The model employed so far is an experimental one, and a number of improvements have suggested themselves during the course of the work with it. Minor ones include, amongst others, better streamlining of the frame, perhaps a greater range of vertical movement of the net frame on the sledge frame, and the attachment of the bucket to the net by means of a bayonet clip. Total weight cannot be much reduced in future models, especially if the apparatus is to be used in any appreciable depth of water, unless a paravane system is mounted which will carry it to and keep it at the bottom without disturbing the flow of water into and through the net. Such paravanes would have to be mounted beyond the range of the current system through the net.

The door system should be improved by eliminating the arms which project out at right angles and render the apparatus rather more clumsy than is necessary, and placing others beneath the frame. In addition, it is possible that the doors may tend to flap whilst the apparatus is being towed and thus influence the water flow into the net and thereby the catch obtained. The doors could therefore be substituted by a vertically moving, flexible shutter operated by such arms acting against the pull of springs.

However, during visual observation of the present apparatus at work in very shallow water, no flapping of the doors was observed and the motion along the bottom was quite satisfactory.

\section{REFERENCES}

Hensen, V., I895. Methodik der Untersuchungen. Ergebnisse der Plankton-Expedition der Humboldt-Stiftung, Bd. I, B, 200 pp.

KüNNE, C., I929. Vergleich der Fangfähigkeit verschiedener Modelle von PlanktonNetzen. Cons. Perm. Int. Explor. Mer, Rapp. Proc. Verb., Vol. 59, 37 pp.

KÜNNE, C., I933. Weitere Untersuchungen zum Vergleich der Fangfähigkeit verschiedener Modelle von vertikal-fischenden Plankton-Netzen. Cons. Perm. Int. Explor. Mer, Rapp. Proc. Verb., Vol. 83, 36 pp.

Ostenfeld, C. H. \& JesPersen, P., I924. Standard net for plankton collections. Cons. Perm. Int. Explor. Mer, Publ. Circ. No. 84, I6 pp.

Russell, F. S., 1928. A net for catching plankton near the bottom. Fourn. Mar. Biol. Assoc., Vol. I5, pp. 105-8. 